\title{
Los beneficios premiales que pueden obtener las personas jurídicas que celebren acuerdos de colaboración eficaz en el marco de la Ley 30737 \\ y su Reglamento
}

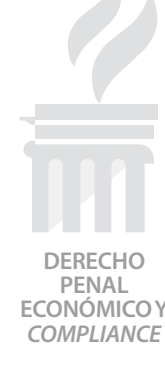

Liliana Calderón Jacinto

Abogada por la Pontificia Universidad Católica del Perú. Máster en Compliance Officer por la Universidad Complutense de Madrid. Máster en Derecho (LL.M.) in Comparative Law por California Western School of Law.

SUMARIO:

I. Introducción.

II. De los alcances de la Ley 30737 , Ley que asegura el pago inmediato de la Reparación Civil a favor del Estado peruano en casos de corrupción y delitos conexos y su Reglamento.

III. El procedimiento de colaboración eficaz en la legislación nacional.

1. Definición y principios.

2. Antecedentes.

3. De los alcances de la colaboración eficaz en la persona jurídica.

IV. De los beneficios premiales que pueden obtener las personas jurídicas de llegar a celebrar su acuerdo de colaboración eficaz.

v. Conclusiones.

* El artículo fue recibido con fecha 19-06-19. 


\section{RESUMEN:}

A lo largo del presente artículo, se desarrollan los beneficios premiales que pueden llegar a generar la Ley 30737 y su reglamento, logrando hasta excluirse a las personas jurídicas del ámbito de aplicación de la misma. Esta Ley, busca asegurar el pago de la reparación civil a favor del Estado peruano, por parte de aquellos hallados culpables en casos de delitos contra la administración pública, corrupción, entre otros. Además, se destaca el concepto del procedimiento de colaboración eficaz dentro de nuestra legislación nacional, describiéndolo como uno de los mecanismos premiales modernos que se introducen para enfrentar el crimen organizado en el Perú.

Palabras clave: Beneficios premiales, personas jurídicas, colaboración eficaz, reparación civil, delitos.

\footnotetext{
ABSTRACT:

Throughout this article, the premial benefits that may be generated by Law 30737 and its regulations are developed, achieving to exclude legal persons from the scope of application thereof. This Law seeks to ensure the payment of civil compensation in favor of the Peruvian State, by those guilty parties in cases of crimes against public administration, corruption, among others. In addition, the concept of the effective collaboration procedure within our national legislation is highlighted, describing it as one of the modern premial mechanisms that are introduced to face organized crime in Perú..

Keywords: Prize benefits, legal persons, effective collaboration, civil compensation, crimes.
}

\section{INTRODUCCIÓN}

En un contexto fuertemente marcado por el destape de grandes escándalos de corrupción, el Estado peruano ha dictado, últimamente, leyes con la finalidad de reprimir la criminalidad empresarial, como es el caso de Ley 30424, Ley que regula la responsabilidad administrativa de las personas jurídicas.

No obstante, si bien es deber del Estado sancionar el delito, también tiene interés en que se reparen los daños que dichas conductas ilícitas hubieren ocasionado, sobre todo si se tiene en cuenta que los más recientes casos de corrupción se han producido en el marco de la adjudicación y ejecución de grandes proyectos de inversión en infraestructura, los cuales son de gran interés nacional en tanto benefician a toda la población.

Así, el Estado aprobó la Ley 30737 que asegura el pago inmediato de la reparación civil a favor del Estado peruano en casos de corrupción y delitos conexos —en adelante, la "Ley 30737", mediante el establecimiento de distintas medidas de restricción para las personas jurídicas o entes jurídicos involucrados en dichos delitos. Sin embargo, esta norma no solo se limita a establecer dichas medidas, sino que, además, ha introducido importantes modificaciones al ré- gimen de colaboración eficaz, con la finalidad de que las personas jurídicas puedan acogerse al mismo, lo que no se encontraba previsto anteriormente en nuestra legislación.

En ese sentido, hoy por hoy, las autoridades competentes cuentan con herramientas eficaces para poder perseguir el delito, los cuales también pueden ser aprovechadas por las personas jurídicas involucradas para lograr la adjudicación de beneficios premiales siempre que cumplan con colaborar en la dilucidación de los hechos delictivos.

En el presente artículo, desarrollaremos las principales disposiciones de la Ley 30737, así como las modificaciones introducidas por esta misma con relación al régimen de colaboración eficaz, y posteriormente, trataremos las ventajas que traen estas nuevas disposiciones.

\section{DE LOS ALCANCES DE LA LEY 30737, LEY QUE ASEGURA EL PAGO INMEDIATO DE LA REPARACIÓN CIVIL A FAVOR DEL ESTADO PERUANO EN CASOS DE CORRUPCIÓN Y DELITOS CONEXOS Y SU REGLAMENTO}

La Ley 30737 y su norma reglamentaria, aprobada mediante Decreto Supremo N ${ }^{\circ}$ 096-2018$\mathrm{EF}$, tienen como finalidad asegurar el pago 
inmediato de la reparación civil a favor del Estado peruano en casos de corrupción y delitos conexos, así como evitar la paralización de los proyectos de inversión pública y la ruptura de la cadena de pagos.

Para lograr tal objetivo, la Ley 30737 ha establecido tres categorías de sujetos, siendo que a cada una de estas se le aplicará un régimen específico consistente en distintas medidas de restricción. El Ministerio de Justicia y Derechos Humanos —en adelante, "MINJUS" — ha elaborado tres listados donde se identifican a las personas jurídicas y entes jurídicos comprendidos en cada una de las referidas categorías. Estos listados son publicados en el portal institucional de la referida entidad y son actualizados el último día hábil de cada mes. Estas publicaciones constituyen el mecanismo en virtud del cual es posible oponer a terceros la condición de un sujeto, que se encuentra comprendido en alguna de las mencionadas categorías, evitando así la inseguridad jurídica.

A continuación, describiremos estas categorías, así como las medidas aplicables a cada una de estas.

- Categoría 1: Se encuentran comprendidas las personas jurídicas o entes jurídicos:

i. Condenados con sentencia firme, en el Perú o en el extranjero, por la comisión de delitos contra la administración pública, lavado de activos o delitos conexos; o equivalentes cometidos en otros países, en agravio del Estado peruano.

ii. Cuyos funcionarios o representantes hayan sido condenados con sentencia firme en el Perú o en el extranjero por la comisión de los delitos antes señalados.

iii. Que, directamente o a través de sus representantes, hubiesen admitido o reconocido la comisión de delitos antes señalados ante autoridad nacional o extranjera competente.

iv. Vinculadas a las personas jurídicas o entes jurídicos señalados anteriormente'.

La incorporación de una persona jurídica o ente jurídico a la Categoría 1 se produce de forma automática tan pronto se verifique alguno de los supuestos de hecho antes señalados.

Los sujetos comprendidos en esta categoría se les aplicará, en líneas generales, las siguientes medidas restrictivas:

a. Suspensión del derecho de efectuar transferencias al exterior, bajo cualquier título, total o parcialmente, del íntegro de los capitales, dividendos o utilidades provenientes de sus inversiones en el país.

b. Autorización previa del MINJUS para efectuar la enajenación, bajo cualquier título, de sus bienes, derechos, acciones u otros valores representativos de derechos, aun cuando hubieren sido transferidos en fideicomisos u otra modalidad semejante; así como la retención del cincuenta por ciento - $50 \%$ - de su precio de venta y posterior depósito en el Fideicomiso de Retención y Reparación-FIRR².

1. Para efectos de la Ley, se consideran personas jurídicas o entes jurídicos vinculados a:

i. Cualquier persona jurídica o ente jurídico que sea propietario de más del diez por ciento — $10 \%$ — de las acciones representativas del capital social o tenedor de participaciones sociales o que directa o indirectamente participe en dicho porcentaje en la propiedad de esta, ya sea directamente o a través de subsidiarias.

ii. Cualquier persona que ejerce control sobre esta y las otras personas sobre las cuales aquella ejerce también un control.

iii. Cualquier persona jurídica o ente jurídico de un mismo grupo económico.

2. El FIRR es un fideicomiso constituido por el Ministerio de Justicia y Derechos Humanos y administrado por el Banco de la Nación, cuya finalidad es recaudar y servir al pago de las reparaciones civiles que correspondan. 
c. Retención de una parte de los pagos que, por cualquier título, deban efectuar las entidades del Estado peruano a su favor de estos sujetos, así como su respectivo depósito en el FIRR.

d. Anotación preventiva en los registros público donde consten los bienes, activos, derechos, acciones u otros valores representativos de derechos, que precise que la adquisición de estos, bajo cualquier título, está sujeta a la autorización previa del MINJUS.

Estos sujetos permanecerán en este régimen hasta que se logre cubrir el monto estimado de la reparación civil a favor del Estado peruano ${ }^{3}$, así como el íntegro de la deuda tributaria exigible.

- Categoría 2: Comprende a las personas jurídicas o entes jurídicos que, en calidad de socios, consorciados o asociados bajo cualquier forma asociativa o societaria, hayan participado en contratos con el Estado peruano de manera conjunta con las personas comprendidas en la Categoría 1, bien durante la etapa de adjudicación o bien de forma posterior a esta.

La incorporación en esta categoría también se produce de manera automática cuando se cumpla el supuesto de hecho descrito.

A diferencia de la Categoría 1, el régimen aplicable a los sujetos de la Categoría 2 no se extiende a las personas vinculadas a estos. Por el contrario, el universo de sujetos que pueden estar comprendidos en esta última categoría es mucho más limitado ${ }^{4}$.

Los sujetos de la Categoría 2 deberán cumplir con las siguientes medidas restrictivas: a. Obligación de constituir un fideicomiso de garantía que asegure el pago de la reparación civil a favor del Estado peruano.

b. Suspensión de efectuar transferencias al exterior, para lo cual son aplicables las mismas reglas previstas para la Categoría 1.

c. Implementación de un modelo de prevención o programa de cumplimiento, cuyo contenido cumpla con lo previsto en la Ley 30424 y su reglamento.

d. Obligación de revelar información y colaborar con la fiscalía a cargo de la investigación, lo que puede incluir poner a su disposición documentos, así como permitir acceso a sus instalaciones, de ser requerido.

Si un sujeto de la Categoría 2 no cumple con la obligación de (i) constituir el fideicomiso de garantía, (ii) implementar el modelo de cumplimiento, o (iii) colaborar en la investigación fiscal, se le aplicará las siguientes medidas de restricción originalmente previstas para sujetos de la Categoría 1:

a. Autorización previa del MINJUS para efectuar la enajenación, bajo cualquier título, de sus bienes, derechos, acciones $\mathrm{u}$ otros valores representativos de derechos, bajo las mismas reglas aplicables para la Categoría 1.

b. Retención de una parte de los pagos que, por cualquier título, deban efectuar las entidades del Estado peruano a su favor de estos sujetos, así como su respectivo depósito en el FIRR.

3. Dicho monto es estimado por la Procurador Público del Estado en atención a los criterios establecidos en el Reglamento.

4. En efecto, esta categoría abarca a los socios, consorciados o asociados con sujetos de la Categoría 1 en tanto hayan participado con estos en contratos con el Estado peruano. No están comprendidos, en consecuencia, aquellos que hayan participado en otro tipo de contratos. 
Cabe señalar que el régimen aplicable a los sujetos de la Categoría 2 será de aplicación hasta que se logre cubrir el monto estimado de la reparación civil a favor del Estado peruano y el íntegro de la deuda tributaria exigible.

- Categoría 3: Aplica a las personas jurídicas o entes jurídicos contra las que se haya iniciado investigación fiscal por la presunta comisión de delitos contra la administración pública, lavado de activos o delitos conexos; o equivalentes, en casos estos hayan sido cometidos en otros países en agravio del Estado peruano, en el desarrollo de proyectos de inversión pública o público-privada, independientemente de su fecha de ejecución.

El régimen de intervención correspondiente a la Categoría 3 es de carácter facultativo. Es decir, la incorporación de personas jurídicas o entes jurídicos en esta categoría se produce en virtud de la solicitud que, de manera voluntaria, dichos sujetos presenten ante el MINJUS, manifestando su interés de acogerse a dicho régimen.

Las medidas de restricción aplicables a los sujetos de la Categoría 3 son las siguientes:

a. Obligación de constituir un fideicomiso con el fin de garantizar el pago de la reparación civil a favor del Estado peruano.

b. Implementación de un modelo de prevención o programa de cumplimiento, cuyo contenido lo previsto en la Ley 30424 y su reglamento.

c. Obligación de revelar información y colaborar con la fiscalía a cargo de la investigación, lo que puede incluir poner a su disposición documentos, así como permitir acceso a sus instalaciones, de ser requerido.

Si un sujeto de la Categoría 3 incumple alguna de las obligaciones antes señaladas, será excluido del presente régimen de intervención.

Finalmente, debemos señalar que los sujetos de la Categoría 3 permanecerán en este régimen de intervención hasta la emisión de la sentencia o resolución que ponga fin al proceso respecto de estos. En caso que la sentencia sea condenatoria, el sujeto de la Categoría 3 pasaría a formar parte de la Categoría 1, siéndole aplicables las medidas correspondientes a esta última.

Luego de haber efectuado esta descripción general de los regímenes previstos en la Ley 30737 , se puede apreciar que, en apariencia, no hay mayor conexión con el proceso penal de colaboración eficaz. Es más, el artículo 25 del Reglamento señala que el cumplimiento de la obligación de revelar de información a las autoridades a cargo de la investigación fiscal —aplicable a los sujetos de la Categoría 2 y la Categoría 3- no se asimila al inicio del proceso penal de colaboración eficaz.

No obstante ello, no debe perderse de vista que el ámbito natural donde puede producirse una colaboración entre el investigado o imputado y las autoridades encargadas es, precisamente, en el marco de un proceso de colaboración eficaz. En efecto, aunque la Ley 30737 no haga una referencia expresa al este proceso mientras describe las medidas aplicables a cada categoría, lo cierto es que este constituye una alternativa legal sumamente valiosa para las personas jurídicas o entes jurídicas afectados por la Ley.

Prueba de ello es que las Disposiciones Complementarias Modificatorias de la Ley 30737 introducen cambios al proceso especial de colaboración eficaz previsto en el Nuevo Código Procesal Penal con el fin de permitir que las personas jurídicas puedan acogerse a dicho régimen, así como el establecimiento de incentivos para fomentar la colaboración con las autoridades.

Teniendo en cuenta ello, a continuación, describiremos los principales aspectos relacionados con el proceso de colaboración eficaz.

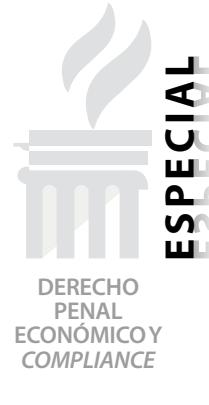




\section{EL PROCEDIMIENTO DE COLABORACIÓN EFICAZ EN LA LEGISLACIÓN NACIONAL}

\section{Definición y principios.}

La colaboración eficaz es un procedimiento especial previsto en nuestra legislación procesal penal, que se ubica dentro de los llamados mecanismos premiales que el Derecho Penal y el Derecho Procesal modernos introducen para enfrentar la criminalidad organizada ${ }^{5}$. Con él se permite, con aprobación judicial posterior, que el Ministerio Público celebre un acuerdo de beneficios y de colaboración con personas naturales y jurídicas, procesados o sentenciados con la finalidad de obtener información relevante para la investigación de un hecho criminal ${ }^{6}$.

Entre los principios más importantes de este procedimiento especial, podemos mencionar a los siguientes?:

i. Eficacia, de tal manera que la información proporcionada debe ser importante y útil para la investigación penal que se realiza, o debe permitir evitar acciones futuras, conocer las circunstancias en que se planificó o ejecutó el delito, o permitir conocer a sus autores o partícipes o los instrumentos o medios utilizados. Si la información no produce tales efectos, carece de eficacia. ii. Oportunidad de la información, pues si ella se aporta tardíamente o ya se conoce a través de otros medios de investigación, no produce beneficio alguno.

iii. Proporcionalidad, se relaciona el beneficio que se otorga con la información o pruebas que aporta el colaborador.

iv. Comprobación, la necesidad de que la información aportada se someta a acciones propias de investigación y corroboración a cargo del fiscal y de la Policía.

v. Formalidad procesal, radicada en el cumplimiento de las normas de procedimiento que incluye la reserva con la que se debe realizar, el control judicial para que la autoridad jurisdiccional verifique la legalidad del acuerdo.

vi. Revocabilidad en el caso de incumplimiento de las obligaciones que se imponen al colaborador que obtuvo beneficios.

\section{Antecedentes.}

En el ámbito internacional, la Convención de las Naciones Unidas contra la delincuencia organizada transnacional, o "Convención de Palermo", recoge en su Artículo $26^{8}$, la exigencia de que

5. SANCHEZ VELARDE, Pablo. La colaboración eficaz en el Nuevo Código Procesal Penal. Vol. I. Lima: Estudios Revista Jurídica del Consejo de Defensa jurídica del Estado, 2011, p. 23.

6. La Ley. 7 claves que debes conocer sobre la colaboración eficaz -2015-. Disponible en: < https://laley.pe/art/2772/7-claves-que-debes-conocer-sobre-la-colaboracion-eficaz->.

7. SANCHEZ VELARDE, Pablo. Op. Cit., p. 24.

8. "Artículo 26. Medidas para intensificar la cooperación con las autoridades encargadas de hacer cumplir la ley 1. Cada Estado Parte adoptará medidas apropiadas para alentar a las personas que participen o hayan participado en grupos delictivos organizados a:

a) Proporcionar información útil a las autoridades competentes con fines investigativos y probatorios sobre cuestiones como: i) La identidad, la naturaleza, la composición, la estructura, la ubicación o las actividades de los grupos delictivos organizados; ii) Los vínculos, incluidos los vínculos internacionales, con otros grupos delictivos organizados; iii) Los delitos que los grupos delictivos organizados hayan cometido o puedan cometer;

b) Prestar ayuda efectiva y concreta a las autoridades competentes que pueda contribuir a privar a los grupos delictivos organizados de sus recursos o del producto del delito.

2. Cada Estado Parte considerará la posibilidad de prever, en los casos apropiados, la mitigación de la pena de las personas acusadas que presten una cooperación sustancial en la investigación o el enjuiciamiento respecto de los delitos comprendidos en la presente Convención. 
el Perú establezca medidas idóneas para promover que las personas investigadas o sospechosas de haber cometido algún acto delictivo, se acerquen a las autoridades para brindar información relevante sobre los hechos, y, en contrapartida, el Estado deberá concederles beneficios.

A nivel nacional, el primer antecedente estuvo dado por la Ley 25384, Ley que preveía la exención y reducción de penas previstas en Artículos 20 y 21 del Código Penal son aplicables a los partícipes en los delitos previstos en las Secciones II, III y IV del Capítulo II del Título XVIII del Libro Segundo del Código Penal. Luego, el Decreto-Ley 25582, que excluía de pena en el juicio, a quien encontrándose incurso en una investigación policial o judicial, proporcione información veraz, oportuna y significativa sobre hechos punibles en agravio del Estado; este Decreto-Ley fue dado el 24 de junio de 1992, en el marco del Gobierno de Emergencia y Reconstrucción Nacional de Alberto Fujimori. Posteriormente, la Ley 27378, promulgada el 20 de diciembre de 2000, estableció beneficios por colaboración eficaz en el ámbito de la criminalidad organizada y fue dada en el marco de los procesos seguidos contra Alberto Fujimori y Vladimiro Montesinos. Finalmente, esta Ley fue derogada por Ley 30077, Ley contra el Crimen Organizado, promulgada el 19 de agosto del 2013. Cabe mencionar que la figura de la colaboración eficaz fue incorporada al Código Procesal Penal y entró en vigencia el 1 de julio de 2014.

\section{De los alcances de la colaboración eficaz para las personas jurídicas.}

La Ley 30737 modifica nueve artículos ${ }^{9}$ del Código Procesal Penal que regulan el denominado "proceso por colaboración eficaz".

Así, el artículo 472 del Código Procesal Penal ${ }^{10}$ establece que el fiscal está facultado a suscribir el acuerdo de beneficios y colaboración con la persona natural o jurídica que se encuentre o no sometida a un proceso penal, así como con quien ha sido sentenciado, en virtud de la colaboración que presten a las autoridades para la eficacia de la justicia penal.

Para que una persona jurídica pueda ser pasible de un acuerdo de colaboración eficaz debe: a) haber abandonado voluntariamente sus actividades delictivas; b) admitir o no contradecir, libre y expresamente, los hechos en que ha intervenido o se le imputen. Aquellos hechos que no acepte no formarán parte del proceso por colaboración eficaz, y se estará a lo que se decida en el proceso penal correspondiente; $y, c$ ) presentarse al Fiscal mostrando su disposición de proporcionar información eficaz.

3. Cada Estado Parte considerará la posibilidad de prever, de conformidad con los principios fundamentales de su derecho interno, la concesión de inmunidad judicial a las personas que presten una cooperación sustancial en la investigación o el enjuiciamiento respecto de los delitos comprendidos en la presente Convención.

4. La protección de esas personas será la prevista en el artículo 24 de la presente Convención.

5. Cuando una de las personas mencionadas en el párrafo 1 del presente artículo que se encuentre en un Estado Parte pueda prestar una cooperación sustancial a las autoridades competentes de otro Estado Parte, los Estados Parte interesados podrán considerar la posibilidad de celebrar acuerdos o arreglos, de conformidad con su derecho interno, con respecto a la eventual concesión, por el otro Estado Parte, del trato enunciado en los párrafos 2 y 3 del presente artículo".

9. Artículos $472,473,474,475,476-A, 477,478,479$ y 480 .

10. "Artículo 472.- Solicitud

1. El Fiscal está facultado a promover o recibir solicitudes de colaboración eficaz y, en su caso, cuando se planteen verbalmente, a levantar las actas correspondientes, a fin de iniciar el procedimiento de corroboración y, si corresponde, a suscribir el Acuerdo de Beneficios y Colaboración, con persona natural o jurídica que se encuentre o no sometida a un proceso penal, así como con quien ha sido sentenciado, en virtud de la colaboración que presten a las autoridades para la eficacia de la justicia penal.

(...)". 
En cuanto a los delitos que pueden ser sometidos a un acuerdo de colaboración eficaz ${ }^{11}$, estos son los siguientes:

i. Asociación ilícita, terrorismo, lavado de activos, delitos informáticos, contra la humanidad, trata de personas y sicariato.

ii. Para todos los casos de criminalidad organizada previstos en la ley de la materia.

iii. Concusión, peculado, corrupción de funcionarios, delitos tributarios, delitos aduaneros contra la fe pública y contra el orden migratorio, siempre que el delito sea cometido en concierto por pluralidad de personas.

iv. Los delitos prescritos en los artículos del 382 al 401 del Código Penal y el artículo 1 de la Ley 30424, modificado por el Decreto Legislativo 1352, cuando el colaborador sea una persona jurídica.

\section{DE LOS BENEFICIOS PREMIALES QUE PUEDEN OBTENER LAS PERSONAS JURÍDICAS DE LLEGAR A CELEBRAR UN ACUERDO DE COLABORACIÓN EFICAZ}

Como cuestión previa, debemos resaltar que, antes de la entrada de la Ley 30424, únicamente las personas naturales podían ser penalmente responsables por la comisión de un delito. Siendo ello así, solo estas podían promover el inicio de un proceso de colaboración eficaz.

Si bien el artículo 105 del Código Penal' ${ }^{12}$ establece que, si un delito fuere cometido en ejercicio de la actividad de cualquier persona jurídica o utilizando su organización para favorecerlo o encubrirlo, el Juez penal puede aplicar, al momento de dictar sentencia, todas o algunas de las medidas o consecuencias accesorias listadas en dicho artículo ${ }^{13}$; lo cierto es que la legislación procesal penal no contemplaba la posibilidad de que una persona jurídica pudiera iniciar un

11. "Artículo 474.- Procedencia

1. Para la aplicación del beneficio por colaboración eficaz, la persona natural y jurídica debe:

[...]

2. Los delitos que pueden ser objeto del Acuerdo, son los siguientes:

[...]

d) Los delitos prescritos en los artículos del 382 al 401 del Código Penal y el artículo 1 de la Ley 30424, modificado por el Decreto Legislativo 1352, cuando el colaborador sea una persona jurídica.

$[\ldots]^{\prime \prime}$.

12. "Artículo 105.- Medidas aplicables a las personas jurídicas

Si el hecho punible fuere cometido en ejercicio de la actividad de cualquier persona jurídica o utilizando su organización para favorecerlo o encubrirlo, el Juez deberá aplicar todas o algunas de las medidas siguientes:

1. Clausura de sus locales o establecimientos, con carácter temporal o definitivo. La clausura temporal no excederá de cinco años.

2. Disolución y liquidación de la sociedad, asociación, fundación, cooperativa o comité.

3. Suspensión de las actividades de la sociedad, asociación, fundación, cooperativa o comité por un plazo no mayor de dos años.

4. Prohibición a la sociedad, fundación, asociación, cooperativa o comité de realizar en el futuro actividades, de la clase de aquellas en cuyo ejercicio se haya cometido, favorecido o encubierto el delito.

La prohibición podrá tener carácter temporal o definitivo. La prohibición temporal no será mayor de cinco años.

"5. Multa no menor de cinco ni mayor de quinientas unidades impositivas tributarias." (*)

Cuando alguna de estas medidas fuera aplicada, el Juez ordenará a la autoridad competente que disponga la intervención de la persona jurídica para salvaguardar los derechos de los trabajadores y de los acreedores de la persona jurídica hasta por un período de dos años.

El cambio de la razón social, la personería jurídica o la reorganización societaria, no impedirá la aplicación de estas medidas".

13. Ello sin perjuicio del pago de la reparación civil — de manera solidaria junto con el sentenciado—, en caso fuera incluida como tercero civilmente responsable. 
proceso de colaboración eficaz para evitar la aplicación de dichas consecuencias.

Sin embargo, fue recién con la entrada en vigencia de la Ley 30737 que se reguló la posibilidad de que las personas jurídicas puedan celebrar Acuerdos de Colaboración Eficaz con el Ministerio Público, siempre que permita la identificación de los involucrados en los hechos delictivos y la información alcanzada sea eficaz, corroborable y oportuna.

En ese sentido, bajo nuestra legislación actual, es perfectamente posible que las personas jurídicas promuevan el inicio de procesos de colaboración eficaz, tanto en el contexto de la aplicación de la Ley 30424, como en el de la aplicación del artículo 105 del Código Penal.

En efecto, con relación a este último aspecto, la Primera Disposición Complementaria Transitoria de la Ley 30737, estableció que las disposiciones del proceso de colaboración eficaz ${ }^{14}$, serán de aplicación a las personas o entes jurídicos pasibles de imponérseles las consecuencias accesorias previstas en el artículo 105 del Código Penal, por la comisión de delitos con anterioridad a la vigencia de la Ley 30424.
En esa línea, nuestra normativa establece los beneficios premiales que pudieran ser otorgados a las personas jurídicas o entes jurídicos, cuyo Acuerdo de Colaboración Eficaz sea aprobado por la Judicatura, son los que se detallan a continuación ${ }^{15}$ :

- $\quad$ Beneficios premiales previstos en el Nuevo Código Procesal Penal -artículo 475, inciso 7-

a) Respecto de la aplicación de las medidas administrativas ${ }^{16}$ previstas en el artículo 5 de la Ley 30424, el Acuerdo de Colaboración Eficaz puede contemplar los siguientes beneficios:

1) Exención de las medidas administrativas aplicables.

2) Disminución por debajo de los parámetros mínimos establecidos.

3) Remisión de la medida para la persona jurídica o ente jurídico que la esté cumpliendo.

4) Otros beneficios establecidos en normas especiales.

14. Disposiciones previstas en la Sección VI del Libro V del Nuevo Código Procesal Penal.

15. Cabe resaltar que los beneficios premiales establecidos en un Acuerdo de Colaboración Eficaz, en ningún caso, pueden implicar la renuncia a la reparación civil que corresponda.

16. "Artículo 5. Medidas administrativas aplicables

El juez, a requerimiento del Ministerio Público, puede disponer, según corresponda, las siguientes medidas administrativas contra las personas jurídicas que resulten responsables de la comisión de los delitos previstos en el artículo 1:

a. Multa no menor al doble ni mayor al séxtuplo del beneficio obtenido o que se espera obtener con la comisión del delito, sin perjuicio de lo dispuesto en el artículo 7.

b. Inhabilitación, en cualquiera de las siguientes modalidades:

1. Suspensión de sus actividades sociales por un plazo no menor de seis meses ni mayor de dos años.

2. Prohibición de llevar a cabo en el futuro actividades de la misma clase o naturaleza de aquellas en cuya realización se haya cometido, favorecido o encubierto el delito. La prohibición podrá tener carácter temporal o definitivo. La prohibición temporal no será menor de un año ni mayor de cinco años.

3. Para contratar con el Estado de carácter definitivo.

c. Cancelación de licencias, concesiones, derechos y otras autorizaciones administrativas o municipales.

d. Clausura de sus locales o establecimientos, con carácter temporal o definitivo. La clausura temporal es no menor de un año ni mayor de cinco años.

e. Disolución". 
- Beneficios premiales previstos en la Ley $\underline{30737}$

a) Respecto de la aplicación de las consecuencias accesorias previstas en el artículo 105 del Código Penal, la Primera Disposición Complementaria Transitoria de la Ley 30737 establece que el Acuerdo de Colaboración Eficaz puede contemplar los beneficios contemplados en el Nuevo Código Procesal Penal, siendo estos los mismos que los previstos en el marco de la aplicación del artículo 5 de la Ley 30424.

b) Respecto de la aplicación de la propia Ley 30737, su Decimotercera Disposición Complementaria Final establece que el Acuerdo de Colaboración Eficaz puede eximir, suspender o reducir la aplicación de esta misma ley, así como extender a las personas jurídicas o entes jurídicos pertenecientes a su mismo grupo económico.

Sobre el particular, el numeral 26.5 del artículo 26 del Reglamento de la Ley 30737 precisa que la recategorización derivada de un proceso de colaboración eficaz se produce con la aprobación del acuerdo por parte del Juez competente, salvo que dicho acuerdo establezca la exclusión de los alcances de la referida norma.

Así, por ejemplo, un sujeto de la Categoría 1 que promueve el inicio de un proce- so de colaboración eficaz, pese a haber sido condenada, puede lograr que se le otorgue el beneficio de exoneración o disminución de sanción y, al mismo tiempo, el beneficio de exclusión de la aplicación de la Ley 30737, de exonerarla de alguna de las medidas de restricción previstas para su categoría o, inclusive, ser recategorizada.

c) Respecto de la aplicación de los impedimentos previstos en los literales $m)^{17} y$ n) ${ }^{18}$ del numeral 11.1 del artículo 11 de la Ley 30225, Ley de Contrataciones del Estado, el Acuerdo de Colaboración puede establecer el beneficio de inaplicación siempre que la persona jurídica:

1) Haya cumplido con el total de las obligaciones laborales y sociales exigibles y vencidas con sus trabajadores.

2) Se haya comprometido con el cumplimiento de sus obligaciones tributarias en un plazo no mayor a 10 años.

3) El Acuerdo de Colaboración Eficaz alcanzado haya sido aprobado durante la etapa de la investigación penal.

Cabe resaltar que, el solo hecho de acogerse al régimen de colaboración eficaz no produce la concesión automática de los beneficios premiales antes señalados, siendo preciso que el colaborador cumpla con proporcionar al Ministerio

17. "m) En todo proceso de contratación, las personas condenadas, en el país o el extranjero, mediante sentencia consentida o ejecutoriada por delitos de concusión, peculado, corrupción de funcionarios, enriquecimiento ilícito, tráfico de influencias, delitos cometidos en remates o procedimientos de selección, o delitos equivalentes en caso estos hayan sido cometidos en otros países. El impedimento se extiende a las personas que, directamente o a través de sus representantes, hubiesen admitido y/o reconocido la comisión de cualquiera de los delitos antes descritos ante alguna autoridad nacional o extranjera competente".

18. “n) En todo proceso de contratación, las personas jurídicas cuyos representantes legales o personas vinculadas que (i) hubiesen sido condenadas, en el país o el extranjero, mediante sentencia consentida o ejecutoriada por delitos de concusión, peculado, corrupción de funcionarios, enriquecimiento ilícito, tráfico de influencias, delitos cometidos en remates o procedimientos de selección, o delitos equivalentes en caso estos hayan sido cometidos en otros países; o, (ii) directamente o a través de sus representantes, hubiesen admitido y/o reconocido la comisión de cualquiera de los delitos antes descritos ante alguna autoridad nacional o extranjera competente. Tratándose de consorcios, el impedimento se extiende a los representantes legales o personas vinculadas a cualquiera de los integrantes del consorcio". 
Público información relevante para la dilucidación de los hechos materia de controversia, así como realizar las acciones de cooperación que le sean requeridas.

Debemos destacar, además, que los beneficios premiales que se hayan establecido en el Acuerdo de Beneficios - suscrito entre el colaborador y el Ministerio Público, y validado judicialmente- no son irrevocables, sino que los mismos pueden ser removidos en caso se detecte que no se han cumplido con las condiciones y obligaciones previstos en el mismo.

Sin perjuicio de ello, el hecho de que el régimen de colaboración eficaz haya sido extendido en beneficio de las personas jurídicas constituye un importante incentivo para que estas puedan cooperar con las autoridades competentes en la dilucidación de los hechos delictivos

\section{CONCLUSIONES}

a) La Ley 30737 ha establecido distintos regímenes para asegurar el pago de la reparación civil a favor del Estado peruano, por parte de aquellas personas jurídicas o entes jurídicos involucrados en casos de delitos contra la administración pública, lavado de activo, entre otros.

b) Esta norma, además, establece modificaciones al régimen de colaboración eficaz con el fin de que las personas jurídicas o entes jurídicos involucrados en dichos delitos puedan ser acreedores de determinados beneficios premiales, en el marco de los Acuerdos de Colaboración Eficaz que hayan logrado suscribir con el Ministerio Público.

c) Los beneficios premiales a los que pueden acceder las personas jurídicas no solo están dirigidas a eximir, suspender o reducir las consecuencias jurídicas directamente derivadas del delito - sanciones-, sino que también pueden llegar a tener el efecto de excluir a la propia persona jurídica de la aplicación de la Ley 30737.

d) De este modo, al establecer importantes incentivos para que las empresas puedan acogerse al régimen de colaboración eficaz, el Estado busca promover la utilización de esta potente herramienta procesal con el propósito de facilitar su labor de persecución del delito. 